\title{
Zoonotic Dermatophytes and Changing Epidemiology of Dermatophytosis in West Africa, an update
}

\author{
Adebowale I Adebiyi ${ }^{1}$ and Harish C Gugnani* ${ }^{2}$ \\ ${ }^{1}$ Department of Veterinary Microbiology, University of Ibadan, Ibadan -200284, Nigeria \\ ${ }^{2}$ Med. Mycology Unit, Department of Microbiology, Vallabhbhai Patel Chest Institute, University of Delhi, Delhi-110007, India . \\ Present Address: J3/45, Rajouri Garden, New Delhi-110027, India \\ *Corresponding author Email: harish.gugnani@gmail.com
}

(Submitted on August 03, 2020; Accepted on October 20, 2020)

\section{ABSTRACT}

\begin{abstract}
In some resource poor countries continuous increase in the traditional practices, such as livestock rearing system, crowded-living and poor housing conditions have heightened uncontrolled access to the infected or asymptomatic animals and increase in the spread of fomites. Consequently, zoonotic fungi can be naturally transmitted between animals and humans, and in some cases cause significant public health problems. Thus, an appraisal of dermatophytosis considered as one of the most common zoonotic infections in humans and animals is needed to realize the burden of this disease in West Africa. A thorough search of existing literature was carried out using the Google search engine and PubMed electronic database to identify and review relevant publications on zoonotic dermatophytosis in West Africa by using the keywords 'dermatophytosis or 'dermatophytes' and 'West Africa'. The Boolean operator 'AND' was used to combine and narrow the searches. Available publications were subsequently reviewed and the findings qualitatively described.Our findings which revealed that dermatophytosis remains a significant infectious condition with varying social and cultural burdens leading to decreased cost value of animals as well as serious outbreaks of diseases in human and animal populations, predisposed by poor traditional practices. Among various factors, continuous increase in livestock keeping, interaction with animals due to socioeconomic and cultural reasons in resource poor countries and rearing of animals in order to augment economic status and livelihood, may continue to play an important role in the occurrence of dermatophytosis. Thus, there is a need to encourage multisectoral approach to investigate epidemiology of dermatophytosis including the role of zoophilic dermatophytes in West Africa.
\end{abstract}

Keywords: Zoonotic dermatophytes, Dermatophytosis pathobiology, epidemiology, West Africa

\section{INTRODUCTION}

In recent years, Zoonotic infections have emerged as a burden for millions of people in recent years, due to re-emerging or novel pathogens often causing outbreaks in the developing world in the presence of inadequate public health infrastructure (Akritidis, 2011). Many zoonotic diseases have significant impact on human health as well as livestock productivity, thereby undermining livelihoods both by causing illness in the household and threatening its livestock and their output (Akritidis, 2011). Dermatophytosis remains one of the most common zoonotic infectious diseases in the world. Several highly specialized pathogenic fungi termed dermatophytes, which are the most common agents of superficial mycoses, have been implicated in this condition. Dermatophytes can affect various parts of the body. They tend to grow in an outward pattern on the skin, thereby producing a ring-like lesion, hence the term 'ringworm'. Lesions are clinically classified according to the site of infection as tinea capitis for scalp, tinea manuum for hands, onychomycosis or tinea unguium for nails, tinea barbae for beard area, and tinea corporis for body including arms and trunk (Hayette and Sacheli, 2015). Dermatophytes may be acquired from humans (anthropophilic species), animals (zoophilic species) or soil (geophilic species). Zoophilic and anthropophilic dermatophytes have evolved from a geophilic origin, with the anthropophilic dermatophytes being the most highly specialized group. Anthropophilic dermatophytes rarely infect animals and they are also restricted to some body parts. Some species including Microsporum audouinii, Trichophyton tonsurans and T. soudanense mostly cause tinea capitis and are rarely isolated from other body sites (Hayette and Sacheli, 2015).The zoophilic Trichophyton mentagrophytes can occur as a geophilic species as evidenced by several reports of its isolation from soil (Wellerand Leifert, 1996; Gugnani et al., 2007; de Silva Pontes et al., 2013), rarely transmitted from soil to humans. Furthermore, Weller and Leifert (1996) described two workers who became infected by the fungus Trichophyton mentagrophytes (identified as T. interdigitale) from seedlings of the coffee plant (Coffea arabica). This draws attention to the possibility of transmitting a fungal infection through contact with plant materials, which could be termed as 'phytophilic'. Several studies have indicated that domestic companion and food animals (including cats, dogs, sheep, goats, cattle, pigs, rabbits, horses, donkeys, ducks and chickens) constitute important reservoir of human dermato-phytic infections in West Africa (Hayette and Sacheli, 2015).

The majority of zoonotic dermatophytoses are caused by four species: Microsporum canis (usually derived from pet animals, particularly cats and dogs), Trichophyton verrucosum (usually derived from cattle), Arthroderma benhamiae (Anamorph: Trichophyton mentagrophytes, usually derived from cats and dogs) and Arthroderma vanbreuseghemii (Anamorph: Trichophyton interdigitale, usually derived from guinea-pigs). Small rodents, rabbits and dogs have also been associated with infection in humans (Bartosch et al., 2019). Infection results most often from direct contact with an infected animal, but it may also be acquired indirectly through contact with a contaminated environment, making it an important occupational mycozoonoses in livestock farmers, dairymen, animal handlers, pet owners and veterinarians (Akritidis, 2011).

It may not be out of place to mention another zoophilic dermatophyte, Trichophyton simii, which can occur in the soil and infect humans. Originally it was described as causing infection in monkeys, poultry, dogs and rodents and humans in India, and also from humans in Sri Lanka in the Indian subcontinent (Gugnani et al., 1967a; 1967b; Gugnani et al., 1971; 1973; 1975; Attapattu, 1989). However, a number of infections caused by $T$. simii in humans and animals not traceable to the Indian subcontinent have now been described from several other countries, including Brazil, USA, France, 
Saudi Arabia, Argentina, Iran and Belgium (Beguin et al., 2013). This dermatophyte has also been recovered frequently from soil in India (Gugnnai et al., 1967a) and once from beach soil in France (Beguin et al., 2013). Apart from the report of $T$. simii infection of guinea baboons (Papio) of African origin in Paris, and its isolation from a single soil sample in Ivory Coast, no case of human and animal infection caused by $T$. simiiis known from Africa (Beguin et al., 2013).

Despite the rare occurrence of severe clinical disease, the lesions can result in disfigurement and pain. Although diagnosis is based on history, clinical appearance and laboratory procedures, e.g. direct microscopic examination of scales, hair or nail and fungal culture, identification of dermatophytes is laborious and needs expertise due to their morphological similarity, variability and phenotypic polymorphism. Recently, molecular tools have been described for the identification of dermatophytes that were sometimes misidentified with traditional methods (Beguin et al., 2013; Hayette and Sacheli, 2015).

Dermatophytes are known to grow best in warm and humid environments, and are thus more common in tropical regions. This perhaps explicates their occurrence in communities in Africa with warm and humid climate, limited water supply, crowded living and poor sanitary conditions (Moto et al., 2015). The continuous increase in some traditional practices in resource poor countries such as livestock rearing system, crowded living and poor housing conditions have heightened uncontrolled access to increase in infected or asymptomatic animals increase and sharing of fomites (Hayette and Sacheli, 2015). Consequently, zoonotic fungi can be naturally transmitted between animals and humans and in some cases cause significant public health problems. Therefore, an appraisal of dermatophytosis considered as one of the most common zoonotic infections in humans and animals (Hayette and Sacheli, 2015) is needed to estimate the burden of this disease in West Africa.

\section{SEARCH CRITERIA}

In the current review, an electronic (computerized) search of existing literature was conducted using the Google search engine and PubMed electronic database to identify and download relevant publications on zoonotic dermatophytosis in West Africa. The key words used were zoonotic dermatophytosis or dermatophytes and West Africa. The Boolean operator 'AND' was used to combine and narrow the searches. Additional information was obtained by searching the medical libraries for journals not listed in the database. The available publications were thereafter reviewed and findings qualitatively described.

\section{LITERATURE REVIEW}

\section{PATHOBIOLOGY OF ZOOPHILIC DERMATOPHYTES}

There are about 40 species of dermatophytes belonging to the three genera, viz. Microsporum, Trichophyton and Epidermophyton, which have the ability to invade the skin and its appendages, hair shaft and nails in humans and similarly the hair shaft and hoof or horn of animals. The dermatophytes secrete proteolytic and lipolytic enzymes to utilize keratin as a source of carbon. Dermatophytes reproduce asexually by forming micro- and macro-conidia borne singly or in groups on specialized conidiogenous cells in the hyphae. Additionally, these fungi produce chlamydospores, spiral hyphae, antler-shaped hyphae (chandeliers), nodular organs, pectinate hyphae and racquet hyphae (Ajello et al., 1966). Most of the dermatophytes form characteristic colonies and pigmentation in culture facilitating presumptive species identification. In addition, some physiological characteristics based on nutritional requirements such as vitamin deficiency can be used to identify some of the dermatophytes (Phillpot, 1977). The sexual stages (perfect stages) of zoophilic dermatophytes are: Arthroderma benhalmiae for Trichophyton mentagrophytes var. Mentagrophytes, Arthroderma simii for Trichophyton simii, Arthroderma otae for Microsporum vanbreuseghemii, and Arthroderma persicolor for Microsporum persicolor. The perfect states of the dermatophytes are members of the Phylum Ascomycota, which includes all the fungi that after nuclear fusion and chromosomal reduction, proceed to form asci and ascospores. They belong to the Class Plectomycetes and Order Onygenales (Padhye and Carmichael, 1969; Alexopoulos et al., 1996). The production of asci occurs inside an ascocarp (cleistothecium or gymnothecium) The wall (peridium) of the cleistothecium is composed of loosely interwoven, thin-walled, light colored hyphae, which is characteristic of the family, Arthroderma taceae which include zoophilic dermatophytes (Weitzman and Summerbell, 1995).

Studies by Rippon and Varadi (1968) demonstrated that certain strains of Microsporum and Trichophyton species produce enzymes which solubilize the keratin and related fibrous proteins found in skin, hair, claws and hoof. Keratin, elastin and collagen make up $25 \%$ of the body weight of mammals. The role of enzymes as virulence factors has also been inferred as they are often found in the tissues of infected animals (Rippon and Varadi, 1968). Investigations to understand the mechanisms of pathogenesis in fungi have resulted in the identification of dipeptidyl peptidase as the virulence factor in dermatophytes (Achterman and White, 2012). Additionally, dermatophytes have been shown to produce melanin or melanin-like compounds, which are predicted to play a role in virulence based on the known role of melanins in other pathogenic fungi (Burmester et al., 2011). Studies on comparative functional genomics of dermatophytes have suggested that dermatophytes appear to have expanded sets of endopeptidases, exopeptidases and secreted proteases, thus emphasizing the role of protein degradation in their mechanism of pathogenesis. In addition, Trichophyton mentagrophytes has been shown to produce xanthomegnin, a toxin previously known to be produced by Aspergillus, in culture and during human infection (Burmester et al., 2011).

\section{SOCIOECONOMIC BURDEN OF ZOOPHILIC DERMATOPHYTES}

Human activities such as hunting, game ranching, forest clearing, and the uncontrolled rearing of domestic animals have increased the chances of transmission of zoonotic parasites (Coulibaly et al., 2014). In addition, changes in vegetation due 
to human activities are believed to play a role in the dynamics of the transmission of zoonotic parasites, leading to serious outbreaks of diseases in human and animal populations. Lesions arising from dermatophytosis have many adverse effects besides the discomfort and unsightly nuisance (Akritidis, 2011). They also prevent the animals from working and interfere with their social use in animal shows and festivities because such animals will not be allowed at shows or other events (because the disease can be transmitted to other animals), thus decreasing the cost value of the infected animal (Seyedmousavi et al., 2018). It has been suggested that the increasing number of reports of infections due to zoophilic dermatophytes in humans are directly linked to the persistence of these fungi in animal reservoirs (Akritidis, 2011; Hayette and Sacheli, 2018). For instance, equine dermatophytosis has considerable zoonotic importance as animals serve as reservoirs for the zoophilic dermatophytes (especially those caused by members of the Microsporum spp. and Trichophyton species) and their infections. Zoophilic dermatophytes such as T. verrucosum, $M$. canis, T. mentagrophytes, $M$. gypseum, and T. equinum have been reported as important causes of human tinea capitis and tinea corporis in many areas of the world (de Silva Pontes et al., 2013).

\section{CULTURA L B URDEN OF ZOOPHILIC DERMATOPHYTES}

With rising urbanization and increased cost of living, there is an increase in the presence of companion and food animals in households with accompanied increased contact and bonding between such animals (such as cats, dogs, cattle, sheep, goats, rabbits and poultry) as a result of co-habitation and feeding with their owners and members of their households in the majority cases as well as the traditional close association between hunters and their dogs. This is more common especially in the rural and peri-urban areas of many developing countries, where a substantial proportion of population is poorly supervised or is free-roaming and may pose a major risk to human health (Mignon and Monod, 2011). Similarly, cats are becoming increasingly popular as pets and companion animals. These animals are acquired from communities and may be affected, visibly or not, by diseases that are transmissible to humans (Adesiji et al., 2019).

\section{EPIDEMIOLOGY OF DERMATOPHYTOSIS IN WEST AFRICA}

Literature search of studies undertaken on both adults and children in West Africa showed tinea corporis to be the most common dermatophyte infection and the most frequent dermatophyte species involved was $T$. mentagrophytes complex (Adefemi et al., 2010). In addition, the two anthropophilic dermatophytes species, $T$. soudanense and $M$. audouinii, were the main etiological agents isolated from tinea capitis cases in different West African countries (Cisse et al., 2006; Fulgence et al., 2013; Coulibaly et al., 2016). The causal agents of tinea capitis in different countries in West Africa are given in table 1, while that of tinea corporis are given in table 2 .

A peculiar feature of dermatophytosis in Africa as evidenced in many studies in West Africa is its high occurrence in children especially between the age group of four and eleven years (M'enan et al., 2002; Adou-Bryn et al., 2004; Ayanbimpe et al., 2008; Fulgence et al., 2013; Ayanlowo and Akinkugbe, 2013). Children of this age group display a higher exposure to dermatophyte sources. Although during the literature survey no studies that addressed the pathophysiology of dermatophytoses, specifically in African setting, were found, yet it has been shown that these children are also more susceptible to dermatophyte infection of the scalp and hair due to the lower fungistatic properties of fatty acids in the sebum, which is due to pre-pubertal hormone characteristics (M'enan et al., 2011). Conversely, scalp hair in adults exhibits increased resistance against dermatophyte colonization due to the fungistatic properties of post-pubertal sebum, which mainly consists of long-chain fatty acids (Mignon and Monod, 2011). This may explain the relative uncommon incidence of tinea capitis in adults than in children (Ayanlowo and Akinkugbe, 2013; Mignon and Monod, 2011).

Furthermore, male children generally are reported to be more affected than female children in West Africa (Adefemi et al., 2011; Ayanlowo and Akinkugbe, 2013). The reported higher incidence in males may be due to more interaction of males with the animals or pets which may be infected or asymptomatic carriers of infections (Adesiji et al., 2019).

Table 1. Agents of tinea capitis in different countries in West Africa

\begin{tabular}{|c|c|c|c|c|c|c|c|c|c|c|c|c|c|}
\hline \multicolumn{14}{|c|}{ Dermatophyte spp identified (\%) } \\
\hline & & & & & & inthropophil & & $\mathbf{G e d}$ & & Zoophilic & & & \\
\hline Country & Pop. Samp. & \begin{tabular}{|l|}
$T$ \\
violaceum \\
\end{tabular} & T. rubrum & \begin{tabular}{|l|}
$T$ \\
tonsurans \\
\end{tabular} & \begin{tabular}{|l|}
$T$. \\
schoelenii \\
\end{tabular} & \begin{tabular}{|l|}
$T$. \\
soudanese
\end{tabular} & \begin{tabular}{|l|}
$\begin{array}{l}\text { M. } \\
\text { audouinii }\end{array}$ \\
\end{tabular} & $\begin{array}{l}M . \\
\text { gypseum }\end{array}$ & \begin{tabular}{|l|} 
M. \\
nanum
\end{tabular} & $\begin{array}{l}T . \\
\text { mentagrophytes }\end{array}$ & \begin{tabular}{|l|} 
T. \\
verrucosum
\end{tabular} & $\begin{array}{c}\text { M. } \\
\text { canis }\end{array}$ & Reference \\
\hline Nigeria & Child. & 8.1 & 18.9 & 18.9 & 8.1 & 5.4 & 24.3 & & & 16.2 & & & Uchegbu et al., 2019 \\
\hline Nigeria (NW) & Child. & & 28.8 & 4.5 & 10.6 & & 10.6 & 12.1 & & 6.1 & 4.5 & 22.7 & Dogo et al., 2016 \\
\hline Nigeria (NC) & Calf, 3 month old & & & & & & & & & & 100.0 & & \begin{tabular}{|l|} 
Daliset al., 2014 \\
\end{tabular} \\
\hline Nigeria (SW) & Child. & & 73.5 & & 100.0 & & 100.0 & & & 94.4 & & & Oke et al., 2014 \\
\hline Nigeria (SW) & Child. & & 34.0 & & 8.0 & & 3.0 & & & 31.0 & 1.0 & 18.0 & Adesijiet al., 2019 \\
\hline Nigeria & Child. & & & & & & 20.7 & & & 51.7 & & & $\begin{array}{l}\text { Ayanlowo and Akinkugbe, } \\
2013\end{array}$ \\
\hline Mali & Child. & & 2.3 & & & 66.1 & & & & & & & Ma"1ga et al., 2001 \\
\hline Mali & & & 3.3 & & & 36.6 & 32.4 & & & 1.9 & & & Coulibalyet al., 2016 \\
\hline Mali & $\begin{array}{l}\text { Hair dressing } \\
\text { tools }\end{array}$ & & & & & 46.7 & 53.3 & & & & & & Coulibaly et al., 2014 \\
\hline Guinea & Child. & 56.7 & & & & & & & & & & & \begin{tabular}{|l|} 
Cisse et al., 2006 \\
\end{tabular} \\
\hline Ivory Coast & & 2.3 & & & & 63.6 & & & & & & & M'enan et al., 2002 \\
\hline Ivory coast & & 1.0 & 1.0 & & & 57.0 & 21.0 & & & 20.0 & & & Adou-Bryn et al., 2004 \\
\hline Ivory Coast & Child. & 1.4 & 0.8 & & & 56.7 & & & & 19.7 & & & Fulgence et al., 2013 \\
\hline Senegal & $\begin{array}{l}\text { Child.and adults } \\
\end{array}$ & & 18.4 & & & 56.2 & & & & 4.6 & & 6.4 & Ndiaye et al., 2015 \\
\hline Senegal & Adults & 2.3 & 4.7 & & & 65.0 & 21.0 & 3.5 & & & 2.3 & & Diopet al., 2019 \\
\hline Ghana & & & & 27.9 & & 29.4 & 25.0 & & & & & & Hogewoning et al., 2006 \\
\hline Togo & & & & & & 20.0 & & & & & & & \begin{tabular}{|l} 
Dupouy-Camet et al., 1988 \\
\end{tabular} \\
\hline
\end{tabular}


Table 2. Agents of tinea corporis in different countries in West Africa

\begin{tabular}{|c|c|c|c|c|c|c|c|c|c|c|c|c|}
\hline \multicolumn{13}{|c|}{ Dermatophyte spp identified (\%) } \\
\hline & & & & & Anthropophili & & Geop & hilic & Zoophilic & & & \\
\hline Country & T. violaceum & T. rubrum & T. tonsurans & T. schoelenii & T. soudanese & M. audouinii & M. gypseum & M. nanum & T. mentagrophytes & T. verrucosum & M. canis & Reference \\
\hline Mali & & & & & 63.8 & & & & 5.0 & & & Coulibaly et al., 2016 \\
\hline Mali & 1.9 & 35.0 & & & 45.0 & 18.0 & & & & & & Coulibaly et al., 2011 \\
\hline Nigeria & & 11.8 & & & & & & & & & & Oke et al., 2014 \\
\hline Nigeria & & & & & & & $18 . .2$ & & 36.0 & & & Ayanbimpe et al., 2008 \\
\hline Nigeria & 3.0 & 54.0 & $5 . .0$ & & & & & & 5.0 & & 16.0 & Adefemi et al., 2011 \\
\hline Nigeria & & & & & 5.6 & & 11.1 & & 5.6 & 22.2 & 11.1 & Maurice et al., 2016 \\
\hline Nigeria (Bida) & & & & & & & 18.2 & & 36.4 & & & Adefemi et $a l, 2010$ \\
\hline Nigeria (Abakali & 2.5 & 41.8 & 3.8 & & & & & & 3.8 & & 12.7 & Oyekaand Eze, 2008 \\
\hline Nigeria (Kano) & & 50.2 & & & & 26.5 & & & & & & Adeleke et al,. 2008 \\
\hline Senegal & & 33.4 & & & 47.3 & & & & & & 1.0 & Kane et al., 2005 \\
\hline
\end{tabular}

The distribution of dermatomycosis, their aetiological agents and the predominating anatomical infection patterns vary with geographical location, age of the animal, environmental factors and cultural aspects (Seyedmousa et al., 2018). Contagiousness among animal populations, high cost of treatment, the difficulty of control measures and the public health consequences of animal dermatomycosis explain their great importance (Seyedmousa et al., 2018). The high resistance of the dermatophyte arthroconidia in the environment, colonization of host species, and the confinement of animals in breeding areas are factors that also influence the endemicity of dermatophytosis (Hayette and Sacheli, 2011).

Several studies have indicated that domestic animals constitute important reservoir of human dermatophytic infections in West Africa (Fulgenceet et al., 2013; Maurice et al., 2016). The most common agents of infection identified were the zoophilic species: Microsporum canis, Trichophyton mentagrophytes and $T$. verrucosum. In addition, these studies revealed that close interactions of humans with domestic animals through nomadic lifestyle, animal farming, and domestic livestock keeping or pet ownership promote the prevalence of dermatophytic infections. In developing countries including those in Africa, Microsporum audouinii, Trichophyton soudanense and Microsporum canis are most frequently isolated aetiological agents of tinea capitis, whereas in most of the European countries these have been displaced by $M$. canis and Trichophyton tonsurans as agents of tinea capitis.

\section{CONCLUSION}

Dermatophytosis remains a significant infectious condition with varying social and cultural burdens leading to decreased cost value of animals as well as serious outbreaks of diseases in human and animal populations. It is predisposed by poor traditional practices that have intensified due to uninhibited access to infected or asymptomatic animals which has increased sharing of fomites. This condition causes considerable economic losses in food and companion animal production as a result of decreased production, treatment cost, premature culling, downgrade of hides and skin and death (Dalis et al., 2014). In addition, the continuous increase in livestock keeping and interaction with animals due to socioeconomic and cultural reasons in resource poor countries in order to augment economic status and livelihood, amongst other factors may continue to play an important role in dermatophytosis occurrence. Thus, there is a need to encourage multisectoral approach to investigate dermatophytosis epidemiology in West Africa (Seyedmousavi et al., 2018).

\section{REFERENCES}

Achterman, R.R. and White, T.C. 2012. Dermatophyte virulence factors: identifying and analyzing genes that may contribute to chronic or acute skin infections. Int. J. Microbiol. Article ID 358305 https://doi.org/10.11 55/2012/358305

Adefemi, S.A. et al. 2010. Superficial fungal infections seen at a tertiary health centre: clinical and mycological studies. West Afr. J. Med. 29: 267-270.

Adefemi, S.A., Odeigah, L.O. and Alabi, K.M. 2011. Prevalence of dermatophytosis among primary school children in Oke-Oyi community of Kwara state. Nig. J. Clin. Pract. 14:23-28.

Adeleke, S., et al. 2008. Dermatophytosis among itinerant Quranic scholars in Kano (Northwest) Nigeria. Nig. Med. Pract. 53(3): 33-35.

Adesiji, Y.O. et al. 2019. Prevalence of tinea capitis among children in Osogbo, Nigeria, and the associated risk factors. Dis.7(1):13. doi:10.3390/diseases7010013.

Adou-Bryn, K.D. et al. 2004. Epidemiology of tinea capitis in Abidjan, Cote d'Ivoire. M'edecine Trop. Rev. Corps Sant'e Colon. 64: 171-175.

Ajello, L. et al. 1966. Laboratory Manual for Medical Mycology. US Department of Health, Education and Welfare, Public Health Service, Communicable Disease Centre, Atlanta, Georgia.

Akritidis, N. 2011. Parasitic, fungal and prion zoonoses: an expanding universe of candidates for human disease. Clin. Microbiol. Infect. 17: 331-335.

Alexopoulos, C.J., Mims, C.W. and Blackwell, M. 1996. Introductory Mycology ( $4^{\text {th }}$ ed.). John Wiley and Sons, Toronto.

Attapattu, M.C. 1989. A study of tinea capitis in Sri Lanka. $J$. Med. Vet. Mycol. 27:27-32.

Ayanbimpe, G.M., Taghir, H., Diya, A. et al. 2008. Tinea capitis among primary school children in some parts of central Nigeria. Mycoses 51: 336-340.

Ayanlowo, O.O. and Akinkugbe, A.O. 2013. Overview of dermatophyte infections at the dermatology outpatient clinic of a tertiary institution in Nigeria. Niger. Q. J. Hosp. Med. 23: 1-6. 
Bartosch, T. et al. 2019. Trichophyton benhamiae and $T$. mentagrophytes target guinea pigs in a mixed small animal stock. Med. Mycol. Case Rep. 23: 37-42.

Beguin, H. et al. 2013. Is Trichophyton simii endemic to the Indian subcontinent? Med. Mycol. 5: 444448.doi.org 10.3109/13693786.2012.737032

Burmester, A. et al. 2011. Comparative and functional genomics provide insights into the pathogenicity of dermatophytic fungi. Genome. Biol. 12(1): article R7.

Cisse, M. et al. 2006. Tinea capitis in department of dermatology and venerology in the university hospital of Donka at Conakry, Guinea. Bull. Soci. 'et'ePathol. Exot. 1990. 99: 32-33.

Coulibaly, O. et al. 2016. Dermatophytosis among school children in three eco-climatic zones of Mali. PLoS. Negl. Trop. Dis. 10: e0004675.

Coulibaly, O. et al. 2011. Dermatomycoses in rural and periurban school children in Mali. Mycoses SI 2: 68-68.

Coulibaly, O. et al. 2014. High dermatophyte contamination levels in hairdressing salons of a West African suburban community. Mycoses 58(2): 65-68.

de Silva Pontes, Z.B.V. et al. 2013. Distribution of dermatophytes from soils of urban and rural areas of cities of Paraiba State, Brazil. Rev. Inst. Med .Trop. Sao Paulo 55(6): 377-383.

Dalis, J.S. et al. 2014. Dermatophytosis caused by Trichophyton verrucosumin a three-month old calf in Shendam, Plateau State, Nigeria. Int. J. Microbiol. Res. 6(1): 515-518.

Diop, A. et al. 2019. Epidemiological, clinical and etiological profile of tinea capitis in adult patients in Dakar, Senegal. Ann. Dermatol. Venereol. 146(2):100-105.

Dogo, J. et al. 2016. Prevalence of tinea capitis among school children in Nok community of Kaduna state, Nigeria. Journal of pathogens 2016: 6 pages. doi.org/10.1155/2016/9601717.

Dupouy-Camet, J. et al. 1988. Epidemiology of tinea of the scalp in Togo. Bull. Soci'et'ePathol. Exot. Ses. Fil. 81: $299-310$

Fulgence, K.K. et al. 2013. Tinea capitis in school children in southern Ivory Coast. Int. J. Dermatol. 52: 456-460.

Gugnani, H.C. et al. 1967a. Occurrence of Athroderma simii in soil and hair of small mammals. Sabouraudia 6 $77-80$

Gugnani, H.C. et al. 1967b. Fungus flora of dermatophytosis and Trichophyton simii infections in North India. Indian J. Dermatol. Venereol. 35: 77-80.

Gugnani, H.C. and Randhawa, H.S. 1973. An epizootic of dermatophytosis caused by Trichophyton simii in poultry. Sabouraudia 11:1-3

Gugnani, H.C. et al. 1971. Isolation of dermatophytes and other keratinophilic fungi from apparently healthy skin coats of domestic animals. Indian J. Med. Res. 5: 169-172.

Gugnani, H.C. et al. 1975. Dermatophytes and other ketratinophilic fungi recovered from small mammals in India. Mykosen 18: 529-536.

Gugnani, H.C. et al. 2007. Occurrence of pathogenic fungi in soil of burrows of rats and of other sites in bamboo plantations in India and Nepal. Mycoses 50:507-511.

Hayette, M. and Sacheli R.2015. Dermatophytosis, trends in epidemiology and diagnostic approach. Curr. Fungal Infect. Rep. doi. org 10.1007/s12281-0150231-4.

Hogewoning, A.A., Duijvestein, M., Boakye, D. et al. 2006. Prevalence of symptomatic tinea capitis and associated causative organisms in the Greater Accra Region, Ghana. Br. J. Dermatol. 154: 784-786.

Kane, A., Ndiaye, D., Niang, S.O. et al. 2005. Tinea in Senegal: an epidemiologic study. Int. J. Dermatol. 44 (suppl. 1): $24-25$

Leung, A.K.C., Hon, K.L., Leong, K.F. et al. 2020. Tinea capitis: an updated review. Recent Pat. Inflamm. Allergy Drug Discov. 14(1):58-68.

M'enan, E.I.H., Zongo-Bonou, O., Rouet, F. et al. 2002. Tinea capitis in school children from lvory Coast (Western Africa). A 1998-1999 cross-sectional study. Int. J. Dermatol. 41: 204-207.

Ma“1ga, I.I., Dicko, D.S., Guindo, M. et al. 2001. Epidemiology of tinea capitis in school circle in Bamako. J. Mycol. M'edicale 11: 143-148.

Maurice, M.N., Ngbede, E.O., Kazeem, H.M. et al. 2016. Equine dermatophytosis: a survey of its occurrence and species distribution among Horses in Kaduna State, Nigeria. Scientifica 2016:7pages. doi.org/10. 1155/2016/6280646 [Article ID 6280646].

Mignon, B. and Monod, M. 2011. Zoonotic infections with dermatophyte fungi. In: Textbook of Zoonoses: Biology, Clinical Practice, and Public Health Control $2^{\text {nd }}$ ed. (Eds: Palmer L, Soulsby L, Torgerson P, David WGB.). Springer, Singapore. doi:10.1093/med $/ 97$ 80198570028.003.0077.

Moto, J.N., Maingi, J.M. and Nyamache, A.K. 2015. Prevalence of tinea capitis in school-going children from Mathare, informal settlement in Nairobi, Kenya. BMC Res. Notes 8: 274.doi.org/10.1186/s 13104-015-1240-7

Ndiaye, M., Diongue, K., Seck, C. et al. 2015. Epidemiological profile of tinea capitis in Dakar (Senegal). A 6-year retrospective study (2008-2013). J. Mycol. Med. 25 (2): $169-176$

Oke, O.O., Onayemi, O., Olasode, O.A., Omisore, A.G. and Oninla, O.A. 2014. The Prevalence and Pattern of Superficial Fungal Infections among School 
Children in Ile-Ife, South-Western Nigeria. Dermatol. Res. Pract. 2014; 842917. doi:10. 1155/ 2014/842917.

Oyeka, C.A. and Eze, I.I. 2008. Fungal skin infections among prison inmates in Abakaliki, Nigeria. Mycoses 51(1): 50-54. https://doi:10.1111/j.1439-0507. 2007.01408.x

Padhye, A.A. and Carmichael, J.W. 1969. Mating behaviour of Trichophyton mentagrophytes varieties paired with Arthroderma benhamiae mating types. Sabouraudia 7: 178-181.

Philpot, C.M. 1977. The use of nutritional tests for dermatophytes. Saubouradia 15 (2):141-50. doi:10. 1080/00362177785190221.9771.

Rippon, J.W. and Varadi, D.P. 1968. The elastases of pathogenic fungi and actinomycetes. J. Invest. Dermatol. 50: $54-58$.
Seyedmousavi, S., Bosco, S.M.G., Hoog, S. et al. 2018. Fungal infections in animals: a patchwork of different situations. Med. Mycol. 56: S165-S187.

Thakur, R. 2013. Tinea capitis in Botswana. Clin. Cosmet. Investig. Dermatol. 6: 37-41.

Uchegbu, U.N., Amah, H.C., Udujih, H.I. And UcheUchegbu, N. 2019. Dermatophytes associated with tinea capitis infection among primary school children in Izombe, Oguta Imo state, Southeastern Nigeria. Br. J. Med. Health Sci. 5 (1): 83-87.

Weller, R. and Leifert, C. 1996. Transmission of Trichophyton interdigitale via an intermediate plant host. $B r . J$. Dermatol. 135 (4): 656-657.

Weitzman, I. and Summerbell, R. 1995. The Dermatophytes. Clinical Microbiology Reviews 8(2): 240-259. 